\title{
ROTULAGEM DE CARDÁPIOS EM RESTAURANTES: INFLUENCIA NAS ESCOLHAS DO CONSUMIDOR ${ }^{1}$
}

\author{
MENU LABELING IN RESTAURANTS: INFLUENCE ON CONSUMER CHOICES
}

\author{
Renata Lima Nascimento² e Deborah Rodrigues Siqueira ${ }^{3}$
}

\section{RESUMO}

O objetivo desta pesquisa foi discutir o uso de rotulagem de cardápios em restaurantes e a influência dessas informações nas escolhas das refeições pelos clientes. Realizou-se uma revisão integrativa da literatura a partir de artigos científicos dos últimos cinco anos, que permitiram a apresentação dos resultados em duas categorias: estudos em que os participantes fizeram escolha real dos alimentos para consumo e estudos nos quais os participantes realizaram escolha hipotética. As pesquisas apontaram resultados divergentes quanto ao uso da rotulagem de cardápios para escolha de alimentos mais saudáveis. Na maioria dos estudos, o uso de rótulos com informações qualitativas, como cores do semáforo ou símbolos de saúde, teve maior impacto na escolha dos consumidores. É importante que a rotulagem seja clara e forneça informações de fácil acesso e entendimento ao consumidor.

Palavras-chave: Informação Nutricional, Planejamento de Cardápio, Rotulagem Nutricional.

\section{ABSTRACT}

The objective of this research was to discuss the use of menu labeling in restaurants and the influence of this information on meal choices by customers. An integrative literature review was carried out based on scientific articles from the last five years, which allowed the presentation of results in two categories: studies in which the participants made a real choice of food for consumption and studies in which the participants made a hypothetical choice. Research has shown divergent results regarding the use of menu labeling to choose healthier foods. In most studies, the use of labels with qualitative information, such as traffic light cores or health symbols, had a greater impact on consumer choice. It is important that the labeling is clear and provides information that is easily accessible and understood by the consumer.

Keywords: Nutritional Facts, Menu Planning, Nutritional Labeling.

1 Trabalho de conclusão de curso de Pós-graduação em Gestão de Unidades de Alimentação e Nutrição. Faculdade IPGS - Instituto de Pesquisas, Ensino e Gestão em Saúde.

2 Autora. Mestra em Alimentos, Nutrição e Saúde. Docente substituta do Curso de Bacharelado em Nutrição, Universidade do Estado da Bahia - UNEB. E-mail: renatalima.nut@gmail.com.

3 Orientadora. Mestra em Nutrição Clínica. Nutricionista no Hospital Universitário Pedro Ernesto, Universidade do Estado do Rio de Janeiro - UERJ. E-mail: drsiqueira_nut@yahoo.com.br. 


\section{INTRODUÇÃO}

O número de pessoas que realizam suas refeições fora de casa aumentou muito no decorrer dos últimos anos, com acréscimo de 8,7\% entre os anos de 2002 e 2018 (IBGE, 2019). Esse crescimento está associado ao estilo de vida da população, com afazeres que demandam maior tempo fora de casa e, consequentemente, menor tempo para dedicar-se ao preparo da alimentação (CAVALCANTE et al., 2017; BEZERRA et al., 2016).

Alimentar-se fora de casa, segundo alguns estudos, esteve associado ao maior consumo energético, de gorduras e sódio, e menor aporte de micronutrientes, principalmente durante o almoço (GORGULHO; FISBERG; MARCHIONI, 2013; LEVINGS; GUNN, 2014; BEZERRA et al., 2016). Essas características da alimentação fora do domicílio estão relacionadas a composição nutricional dos alimentos disponíveis para consumo, com alta densidade energética, reduzido teor de fibras e maior tamanho das porções, mas também com a escolha do consumidor, que está exposto a maior variedade de alimentos de alta palatabilidade (BEZERRA et al., 2016).

A rotulagem de cardápios vem sendo apontada por alguns estudos como uma ferramenta útil para auxiliar os consumidores na escolha dos alimentos ao realizar refeições fora do domicílio, considerando que estabelecer o valor nutricional das preparações e exibir estas informações aos consumidores talvez seja uma forma de auxiliá-los em escolhas mais saudáveis (LACHAT et al., 2011; TEMPLE et al., 2011; BLEICH; WOLFSON; JARLENSKI, 2015). Entretanto, e apesar de a rotulagem de cardápios ser obrigatória em alguns países, a exemplo da Austrália, Canadá, Irlanda, Arábia Saudita, Coréia do Sul, Taiwan, Emirados Árabes Unidos, e Estados Unidos da América, não há consenso sobre essa ser uma medida efetiva para o controle da obesidade e Doenças Crônicas Não Transmissíveis (DCNT) (PATIÑO et al., 2020).

Nesse contexto, além de rotular os cardápios apresentando as informações nutricionais (valor energético das preparações e teor de sódio, em sua maioria), diferentes estudos também avaliam a rotulagem de cardápios a partir da classificação dos alimentos de acordo com as cores do semáforo, através de símbolos que sinalizam os alimentos saudáveis, e até com informações relacionadas às necessidades energéticas diárias (FERNANDES et al., 2016).

Considerando que a obesidade e DCNT têm grande prevalência na população brasileira, e que a alimentação inadequada está associada a estas doenças (BRASIL, 2018), este estudo apresenta grande relevância, por proporcionar discussões acerca da forma como melhores escolhas alimentares podem ser incentivadas no consumo alimentar fora do domicílio. Assim, o objetivo deste estudo é discutir o uso de rotulagem de cardápios em restaurantes e a influência dessas informações nas escolhas das refeições pelos clientes. 


\section{MATERIAL E MÉTODOS}

Trata-se de um estudo de revisão integrativa da literatura, realizado através de seis fases, sendo: 1) elaboração de pergunta norteadora, 2) busca na literatura, 3) coleta de dados, 4) análise crítica dos estudos incluídos, 5) discussão dos resultados e 6) apresentação da revisão integrativa. Realizou-se a busca na Biblioteca Virtual em Saúde (BVS) e no PubMed, nas bases de dados eletrônicos da Literatura Latino-Americana e do Caribe em Ciências da Saúde (LILACS) e do Medical Literature Analysis and Retrievel System Online (MEDLINE). Utilizaram-se os seguintes descritores e suas combinações: "restaurantes”, “serviços de alimentação", “cardápios”, “informação nutricional”, "rotulagem”, "rotulagem nutricional".

Como critérios de inclusão, foram selecionados estudos científicos indexados nos referidos bancos de dados entre os anos de 2015 a 2019, em português, inglês e espanhol. Foram excluídos estudos realizados com crianças, adolescentes e participantes enfermos, assim como os realizados em fast foods.

A partir da busca e coleta de dados, foram selecionados 12 estudos, posteriormente lidos e analisados criticamente. Essa análise permitiu a apresentação e discussão dos resultados em duas categorias: estudos em que os participantes fizeram escolhas hipotéticas de alimentos e aqueles em que os participantes fizeram a escolha real dos alimentos para consumo. A discussão foi complementada com informações técnico-científicas obtidas a partir de artigos, livros e sites de órgãos oficiais.

\section{RESULTADOS E DISCUSSÃO}

Dentre os estudos selecionados, três deles realizaram experimentos em que os participantes fizeram seleção hipotética de alimentos para compor sua refeição sendo, por isso, considerados estudos de laboratório, e nove realizaram experimentos em restaurantes comerciais ou institucionais, onde foi avaliada de forma prática a escolha do consumidor quando apresentado ao cardápio com rotulagem. Os estudos foram apresentados na Quadro 1. 
Quadro 1 - Apresentação da síntese dos artigos incluídos na revisão integrativa.

\begin{tabular}{|c|c|c|c|c|c|}
\hline Autores & Objetivos & $\begin{array}{c}\text { Delineamento do } \\
\text { estudo }\end{array}$ & Rotulagem & População & Principais resultados \\
\hline \multicolumn{6}{|c|}{ Escolha hipotética dos alimentos } \\
\hline PEREZ et al., 2017 & $\begin{array}{l}\text { Avaliar a utilidade } \\
\text { potencial da rotula- } \\
\text { gem de cardápios na } \\
\text { seleção de alimen- } \\
\text { tos pelos clientes. }\end{array}$ & Transversal. & Valor calórico. & $\begin{array}{l}\text { Funcionários de } \\
\text { diversas empresas. }\end{array}$ & $\begin{array}{l}\text { As informações ca- } \\
\text { lóricas nos cardápios } \\
\text { reduziram a ingestão } \\
\text { calórica das refeições } \\
\text { de forma acentuada. }\end{array}$ \\
\hline REALE; FLINT, 2016 & $\begin{array}{l}\text { Examinar o impacto } \\
\text { do design da rotu- } \\
\text { lagem de cardápios } \\
\text { na atenção visual, } \\
\text { escolha de alimentos } \\
\text { e reconhecimento de } \\
\text { informações. }\end{array}$ & Experimental. & $\begin{array}{l}\text { Valor calórico, } \\
\text { cores do semáfo- } \\
\text { ro, e logotipos de } \\
\text { orientação. }\end{array}$ & $\begin{array}{l}\text { Estudantes univer- } \\
\text { sitários. }\end{array}$ & $\begin{array}{l}\text { As rotulagens de cardá- } \\
\text { pios diretivas e semidi- } \\
\text { retivas tiveram maior } \\
\text { impacto nas escolhas } \\
\text { dos participantes que } \\
\text { as não diretivas - valor } \\
\text { calórico. }\end{array}$ \\
\hline $\begin{array}{l}\text { STRELETSKAYA } \\
\text { et al., } 2015\end{array}$ & $\begin{array}{l}\text { Mensurar o impac- } \\
\text { to de três diferentes } \\
\text { formatos de rotula- } \\
\text { gem na mudança de } \\
\text { escolha de alimen- } \\
\text { tos em refeições } \\
\text { fora de casa. }\end{array}$ & Experimental. & $\begin{array}{l}\text { Valor calórico, } \\
\text { informações nutri- } \\
\text { cionais completas, } \\
\text { e alegações relacio- } \\
\text { nadas à saúde. }\end{array}$ & $\begin{array}{l}\text { Estudantes univer- } \\
\text { sitários. }\end{array}$ & $\begin{array}{l}\text { Não houve mudança } \\
\text { na densidade energé- } \\
\text { tica selecionada, mas } \\
\text { houve menor teor de } \\
\text { calorias vazias nas } \\
\text { rotulagens com infor- } \\
\text { mações nutricionais } \\
\text { completas e alegações } \\
\text { relacionadas à saúde. }\end{array}$ \\
\hline \multicolumn{6}{|c|}{ Escolha real dos alimentos } \\
\hline $\begin{array}{l}\text { THORNDIKE } \\
\text { et al., } 2019\end{array}$ & $\begin{array}{l}\text { Determinar se a im- } \\
\text { plementação de um } \\
\text { programa de alimen- } \\
\text { tação saudável no } \\
\text { refeitório do hospital } \\
\text { estava associada à } \\
\text { redução de calorias } \\
\text { compradas pelos } \\
\text { funcionários. }\end{array}$ & Coorte. & $\begin{array}{l}\text { Cores do semáforo } \\
\text { e arquitetura de } \\
\text { escolha. }\end{array}$ & $\begin{array}{l}\text { Funcionários de } \\
\text { hospital. }\end{array}$ & $\begin{array}{l}\text { Redução consistente do } \\
\text { valor calórico adquiri- } \\
\text { do, principalmente dos } \\
\text { alimentos rotulados } \\
\text { com a cor vermelha. }\end{array}$ \\
\hline $\begin{array}{l}\text { TURNWALD; } \\
\text { CRUM, } 2019\end{array}$ & $\begin{array}{l}\text { Comparar os } \\
\text { efeitos da rotulagem } \\
\text { tradicional focada } \\
\text { na saúde versus } \\
\text { rotulagem focada no } \\
\text { sabor sobre seleção } \\
\text { e prazer do consumo } \\
\text { de alimentos saudá- } \\
\text { veis pelos adultos. }\end{array}$ & Métodos mistos. & $\begin{array}{l}\text { Rotulagem focada } \\
\text { em saúde versus } \\
\text { rotulagem focada } \\
\text { em sabor. }\end{array}$ & $\begin{array}{l}\text { Diferentes configu- } \\
\text { rações de restau- } \\
\text { rantes. }\end{array}$ & $\begin{array}{l}\text { A rotulagem focada em } \\
\text { sabor demonstrou ser } \\
\text { uma estratégia simples } \\
\text { e eficiente para pro- } \\
\text { mover mudanças nas } \\
\text { escolhas e estimular o } \\
\text { consumo de alimentos } \\
\text { saudáveis. }\end{array}$ \\
\hline
\end{tabular}




\begin{tabular}{|c|c|c|c|c|c|}
\hline $\begin{array}{l}\text { MAZZOCO } \\
\text { et al., } 2018\end{array}$ & $\begin{array}{l}\text { Criar ferramenta } \\
\text { que permita fácil } \\
\text { identificação das } \\
\text { escolhas mais } \\
\text { saudáveis durante } \\
\text { a montagem das } \\
\text { refeições em servi- } \\
\text { ços de alimentação } \\
\text { e permitir que os } \\
\text { consumidores } \\
\text { componham seus } \\
\text { pratos com escolhas } \\
\text { mais saudáveis. }\end{array}$ & Experimental. & $\begin{array}{l}\text { Cores do semáforo, } \\
\text { grupo de alimentos, } \\
\text { tamanho de porção } \\
\text { e ingredientes. }\end{array}$ & $\begin{array}{l}\text { Clientes em } \\
\text { estabelecimento } \\
\text { comercial. }\end{array}$ & $\begin{array}{l}\text { Foram identificadas } \\
\text { mudanças no compor- } \\
\text { tamento do consumi- } \\
\text { dor, principalmente } \\
\text { provenientes do uso } \\
\text { das cores, tamanho } \\
\text { da porção e lista de } \\
\text { ingredientes. }\end{array}$ \\
\hline $\begin{array}{l}\text { SEWARD; BLOCK; } \\
\text { CHATTERJEE, } 2018\end{array}$ & $\begin{array}{l}\text { Avaliar as percep- } \\
\text { ções dos alunos } \\
\text { quanto aos rótulos } \\
\text { dos semáforos } \\
\text { nos refeitórios das } \\
\text { faculdades. }\end{array}$ & $\begin{array}{l}\text { Transversal - méto- } \\
\text { dos mistos. }\end{array}$ & Cores do semáforo. & $\begin{array}{l}\text { Estudantes univer- } \\
\text { sitários. }\end{array}$ & $\begin{array}{l}\text { Apesar da aceitação e } \\
\text { concordância que infor- } \\
\text { mações são necessárias, } \\
\text { estudantes questionaram } \\
\text { a cor vermelha como } \\
\text { "chocante" e levantaram } \\
\text { a hipótese de influenciar } \\
\text { negativamente em trans- } \\
\text { tornos alimentares. }\end{array}$ \\
\hline $\begin{array}{l}\text { SCOURBOUTAKOS } \\
\text { et al., } 2017\end{array}$ & $\begin{array}{l}\text { Testar o efeito de } \\
\text { uma intervenção } \\
\text { que incluiu educa- } \\
\text { ção nutricional e } \\
\text { rotulagem das be- } \\
\text { bidas nas escolhas } \\
\text { alimentares dos } \\
\text { alunos. }\end{array}$ & Transversal. & $\begin{array}{l}\text { Rotulagem de calo- } \\
\text { rias equivalentes de } \\
\text { atividade física. }\end{array}$ & $\begin{array}{l}\text { Estudantes univer- } \\
\text { sitários. }\end{array}$ & $\begin{array}{l}\text { Houve decréscimo na } \\
\text { compra de bebidas } \\
\text { açucaradas e aumento } \\
\text { do consumo de água. }\end{array}$ \\
\hline VIEIRA et al., 2017 & $\begin{array}{l}\text { Descrever o efeito } \\
\text { de rotulagem do } \\
\text { gasto calórico no } \\
\text { comportamento real } \\
\text { de compra de ali- } \\
\text { mentos, bem como } \\
\text { na atividade física. }\end{array}$ & Coorte. & $\begin{array}{l}\text { Rotulagem de calo- } \\
\text { rias equivalentes de } \\
\text { atividade física e } \\
\text { valor calórico. }\end{array}$ & $\begin{array}{l}\text { Funcionários em } \\
\text { refeitório da em- } \\
\text { presa. }\end{array}$ & $\begin{array}{l}\text { Informações de } \\
\text { calorias talvez não } \\
\text { sejam suficientes para } \\
\text { promover mudanças na } \\
\text { escolha dos alimentos. }\end{array}$ \\
\hline KERINS et al., 2016 & $\begin{array}{l}\text { Examinar o impac- } \\
\text { to da rotulagem de } \\
\text { cardápio baseada } \\
\text { em ícones no } \\
\text { comportamento de } \\
\text { compra do consu- } \\
\text { midor. }\end{array}$ & $\begin{array}{l}\text { Quase-experimen- } \\
\text { tal. }\end{array}$ & Ícones de saúde. & $\begin{array}{l}\text { Clientes em } \\
\text { estabelecimentos } \\
\text { comerciais. }\end{array}$ & $\begin{array}{l}\text { Não foram encontradas } \\
\text { diferenças significati- } \\
\text { vas no comportamento } \\
\text { de compra do consumi- } \\
\text { dor após rotulagem. }\end{array}$ \\
\hline
\end{tabular}




\begin{tabular}{|c|c|c|c|c|c|}
\hline PRATT et al., 2016 & $\begin{array}{l}\text { Determinar a efi- } \\
\text { cácia do uso de um } \\
\text { gráfico bidimensio- } \\
\text { nal para apresentar } \\
\text { valores quantitati- } \\
\text { vos de } 2 \text { nutrientes } \\
\text { selecionados. }\end{array}$ & Experimental. & $\begin{array}{l}\text { Gráfico bidimen- } \\
\text { sional. }\end{array}$ & $\begin{array}{l}\text { Estudantes univer- } \\
\text { sitários. }\end{array}$ & $\begin{array}{l}\text { A maioria dos partici- } \\
\text { pantes entendeu com- } \\
\text { pletamente o gráfico. A } \\
\text { apresentação gráfica } \\
\text { melhorou o teor nu- } \\
\text { tricional das refeições } \\
\text { compradas. }\end{array}$ \\
\hline $\begin{array}{l}\text { SEWARD; BLOCK; } \\
\text { CHATTERJEE, } 2016\end{array}$ & $\begin{array}{l}\text { Analisar se a rotu- } \\
\text { lagem de semáforos } \\
\text { e as intervenções } \\
\text { na arquitetura de } \\
\text { escolha melhora- } \\
\text { ram as escolhas } \\
\text { alimentares entre } \\
\text { os estudantes de } \\
\text { uma universidade } \\
\text { do nordeste dos } \\
\text { EUA. }\end{array}$ & Experimental. & $\begin{array}{l}\text { Cores do semáfo- } \\
\text { ro, arquitetura de } \\
\text { escolha e adesivos } \\
\text { de prato saudável. }\end{array}$ & $\begin{array}{l}\text { Estudantes univer- } \\
\text { sitários. }\end{array}$ & $\begin{array}{l}\text { Não foi possível iden- } \\
\text { tificar melhorias nas } \\
\text { escolhas alimentares } \\
\text { dos estudantes. }\end{array}$ \\
\hline
\end{tabular}

Fonte: Construção das Autoras

\section{ESTUDOS EXPERIMENTAIS COM ESCOLHA HIPOTÉTICA DOS ALIMENTOS}

Perez et al. (2017) avaliaram o uso da rotulagem de cardápios por funcionários de diferentes empresas que almoçavam fora ao menos uma vez por semana e os resultados sugeriram que as informações calóricas poderiam ser úteis na seleção de alimentos. Neste estudo, após serem expostos ao cardápio online sem e com rotulagem, $49 \%$ dos participantes decidiram reduzir as calorias totais da refeição escolhida (redução de 39,2\%), 47\% mantiveram e 4\% aumentaram a ingestão de calorias. Dentre os participantes que reduziram o valor calórico consumido, 70\% eram do sexo feminino, o que refletiu maior interesse das mulheres em alimentação saudável e controle do peso.

A rotulagem de cardápios parece afetar de formas distintas os diferentes públicos. Alguns estudos sugeriram que seu uso seria maior por mulheres, pessoas de maior renda, maior escolaridade e que têm mais consciência com relação a saúde (BLEICH et al., 2017; FENG; FOX, 2018). Assim, tornar as informações nutricionais mais claras e acessíveis pode ser uma alternativa para incentivar o uso da rotulagem nutricional em restaurantes (BLEICH et al., 2017).

Reale e Flint (2016) apontaram que a rotulagem de cardápio seria uma opção viável para influenciar nas escolhas do consumidor, mas a forma como as informações são apresentadas tem impactos distintos na escolha dos alimentos. No estudo realizado pelos autores, as informações foram apresentadas de forma não diretiva, com apresentação usual de rótulos, semidiretiva, utilizando as cores do semáforo, e diretiva, com logotipos de saúde. Apesar de a atenção visual e o reconhecimento das informações não ter variado significativamente de acordo com o design do rótulo, o uso de cores do semáforo e logotipos de saúde afetaram a escolha dos consumidores, fazendo-os selecionar refeições menos calóricas do que aqueles expostos a rótulos simples, com texto utilizando fonte preta. 
A redução da densidade energética dos alimentos escolhidos também foi observada no estudo de Streletskaya et al. (2015), que expôs os participantes inicialmente a um cardápio sem rotulagem e, posteriormente, a diferentes formatos de rotulagem. Enquanto o cardápio rotulado com valores calóricos obteve a maior redução na densidade energética das refeições escolhidas hipoteticamente, a rotulagem nutricional completa e com alegações de saúde levaram à maior redução de calorias vazias, calorias provenientes de gorduras e de gorduras saturadas, além do rótulo com valores nutricionais completos ter sido o único a reduzir o conteúdo de açúcares adicionados. Vale ressaltar que ao publicar apenas valor calórico das preparações, os pesquisadores perceberam redução do aporte de fibras nas escolhas dos participantes concomitante à redução da densidade energética.

Segundo os autores, os estudos têm como limitação a escolha dos alimentos ter sido hipotética, realizada em laboratório. De acordo com Bleich et al. (2017), a pesquisa mais recomendada para este tipo de estudo seria um experimento controlado aleatoriamente. Entretanto, os mesmos identificaram escassez de estudos bem planejados para afirmar que a rotulagem do cardápio estimula o consumo de alimentos menos calóricos e se este estaria associado a uma população mais saudável.

É importante observar que a redução calórica sozinha, como discutido por Streletskaya et al. (2015), não está diretamente relacionada a melhores escolhas alimentares ou a indivíduos saudáveis. Alimentação saudável não é apenas a ingestão de nutrientes e inclui, além do equilíbrio entre o consumo de nutrientes e dos diversos alimentos e seus grupos alimentares, as dimensões sociais e culturais da alimentação (BRASIL, 2014).

\section{ESTUDOS EXPERIMENTAIS COM ESCOLHA REAL DOS ALIMENTOS}

A maioria dos estudos sobre rotulagem de cardápios foca em discutir a informação nutricional em restaurantes segundo a perspectiva do valor calórico das refeições (KERINS et al., 2016; PRAT et al., 2016). Uma revisão sistemática, realizada por Fernandes et al. (2016), concluiu que a influência da informação nutricional se mostrou parcial, restrita a determinado assunto ou alimento - restrição calórica em alguns estudos, aumento do consumo de frutas e hortaliças em outros.

Nos refeitórios de restaurantes institucionais, local em que a rotulagem de cardápios foi mais eficaz, a informação apresentada de forma qualitativa (símbolos de coração para alimentos considerados mais saudáveis ou uso de cores do semáforo para identificar alimentos que devem ser priorizados ou não) obteve melhores resultados que na forma quantitativa (valor calórico das preparações) (FERNANDES et al., 2016).

Kerins et al. (2016) avaliaram o uso de ícones na rotulagem de cardápios e a sua influência no comportamento de escolha do consumidor. Os ícones classificaram os alimentos como amigáveis ao colesterol, à pressão arterial, ao peso, ao diabetes ou como melhor escolha para o coração e a venda 
foi avaliada por quatro semanas. Não foram encontradas diferenças significativas entre as vendas antes e após a rotulagem do cardápio.

A rotulagem de cardápios com o equivalente de calorias da atividade física foi realizada em dois dos estudos encontrados (VIEIRA et al., 2017; SCOURBOUTAKOS et al., 2017). Segundo Viera et al. (2017), apenas a rotulagem com o gasto calórico talvez não seja suficiente para influenciar nas escolhas do consumidor. É necessário que haja entendimento das informações apresentadas e que o comensal saiba como aquela informação pode se encaixar no seu dia a dia, afinal, outras variáveis influenciam na escolha do consumidor, como o sabor, o tempo, o custo e as preferências alimentares, sendo necessário também que o consumidor possa confiar na rotulagem apresentada (KERINS et al., 2016; VIERA et al. 2017).

Scourboutakos et al. (2017) rotularam apenas as bebidas do cardápio com o número de minutos necessários para a queima das calorias ofertadas por cada uma. Houve redução significativa na proporção de comensais que consumiram bebidas açucaradas após a intervenção. Entretanto, diferente de Viera et al. (2017), foi realizada atividade de educação nutricional concomitante à rotulagem. Os estudantes foram estimulados, através de cartazes e antes da rotulagem do cardápio, a beber água quando estavam com sede. Apesar desse resultado, não se pôde afirmar que os estudantes trocaram a bebida açucarada devido a rotulagem, podendo ter existido também sinergia entre diversos fatores que influenciam nas escolhas alimentares.

Segundo um estudo sobre crenças em saúde (Health Belief Model), realizado por Jeong e Ham (2018), variáveis como ameaças à saúde percebidas na escolha dos alimentos e benefícios percebidos no uso das informações nutricionais afetaram positivamente o uso dos rótulos, enquanto as barreiras percebidas ao uso afetaram negativamente o uso de rotulagem de cardápios pelos clientes (JEONG; HAM, 2018). Além disso, informações sobre os ingredientes da preparação, conteúdo de gorduras e teor de sódio podem ser complementares ou até mais importantes para o consumidor que o valor energético dos alimentos, assim como preferências pessoais, restrições alimentares e tipos de restaurantes (FERNANDES et al., 2015).

Uma ferramenta foi elaborada por Mazocco et al. (2018) com objetivo de facilitar as escolhas dos consumidores em restaurantes self-service. As preparações de um restaurante comercial que vendia comida por quilograma foram rotuladas com placas segundo as cores do semáforo, os ingredientes das preparações, tamanho de porção e os grupos de alimentos aos quais pertenciam, seguindo as recomendações de consumo baseadas no Guia Alimentar para População Brasileira (BRASIL, 2014) e no Guia My plate (USDA, 2011), afim de recomendar o “prato de almoço mais saudável”. Mais da metade dos consumidores (54,5\%) relataram mudanças positivas nas escolhas alimentares após o uso das informações nutricionais.

Thorndike et al. (2019) também encontraram resultados positivos ao rotular cardápios qualitativamente, utilizando as cores do semáforo e a arquitetura de escolha (alimentos mais saudáveis no começo da linha de distribuição). Os resultados obtidos demonstraram que a rotulagem do cardápio 
esteve associada, durante todo o período de dois anos, ao decréscimo do consumo de calorias provenientes, principalmente, dos itens rotulados com a cor vermelha.

Seward, Block e Chatterjee (2016 e 2018) realizaram estudos em refeitórios de uma Universidade. No primeiro, os autores investigaram, durante treze semanas, o efeito da rotulagem com cores do semáforo, arquitetura da escolha e placas de alimentação saudável na escolha dos estudantes. Os rótulos não influenciaram nas escolhas alimentares, apesar de a maioria dos estudantes terem afirmado que a rotulagem era útil e que deveria continuar vigente após o estudo. No segundo estudo foram realizados grupos focais com os estudantes, que levantaram questionamentos quanto ao real benefício da rotulagem através das cores vermelha, verde e amarela. Segundo alguns dos participantes, a cor vermelha poderia causar julgamento entre os comensais e até mesmo contribuir para piora de pessoas com distúrbios alimentares.

Diante disso, os autores sugeriram que talvez uma rotulagem com caráter positivo ou uma intervenção criativa na arquitetura da distribuição fossem mais interessantes para serem utilizadas com este público jovem e que a educação nutricional tornaria a rotulagem mais eficaz, visto que o sabor, muitas vezes independentemente do valor nutricional da refeição, foi citado como principal condição para escolha dos alimentos a serem consumidos (SEWARD; BLOCK; CHATTERJEE, 2018).

Turnwald e Crum (2019), considerando que o consumidor prioriza o sabor no momento da escolha dos alimentos, e que a rotulagem dos cardápios focada em saúde não se adaptaria às suas preferências, publicaram uma pesquisa descrevendo resultados de quatro estudos de campo que avaliaram o uso da rotulagem de cardápios sob uma perspectiva diferente dos estudos usuais, focando no sabor ao invés da saúde. O primeiro e segundo estudos avaliaram a rotulagem de saúde versus a rotulagem de sabor, enquanto o terceiro estudo avaliou a rotulagem de saúde e de sabor em pratos onívoros versus vegetarianos a longo prazo, e o quarto estudo o quanto a rotulagem de sabor poderia melhorar a aceitação o sabor percebido do alimento saudável. A rotulagem focada no sabor aumentou a seleção de alimentos saudáveis em 38\% em comparação com a rotulagem tradicional focada na saúde, podendo ser considerada uma boa estratégia de rotulagem de cardápios (TURNWALD; CRUM, 2019).

A representação gráfica da composição nutricional dos alimentos num refeitório de uma universidade possibilitou redução do valor calórico e do teor de gorduras saturadas dos alimentos adquiridos pelos estudantes sem reduzir valores proteicos (PRAT et al., 2016). Uma apresentação visual do valor nutricional permitiu aos comensais processar as informações de forma mais efetiva que uma apresentação através de tabelas e números. Segundo os autores, o uso das cores do semáforo para diversos nutrientes poderia ser confuso, levando o consumidor a ter que analisar diversas informações ao mesmo tempo. Por isso, a representação gráfica bidimensional poderia ser interessante, por permitir posicionar valores quantitativos de dois nutrientes de vários alimentos em um único espaço (PRAT et al., 2016). Apesar de 83,8\% dos participantes deste estudo terem afirmado entender o gráfico, a 
população tinha um alto nível educacional. Portanto, talvez os mesmos resultados pudessem não ser obtidos com diferentes públicos.

Segundo os estudos apresentados, as evidências de que a rotulagem nutricional em restaurantes pode influenciar em escolhas mais saudáveis pelos indivíduos são variáveis, principalmente porque o impacto não é uniforme entre os indivíduos. Vários fatores intrínsecos ao consumidor estão associados, como renda, escolaridade, patologias, necessidades individuais, sexo, entre outros. Mas os resultados podem ser afetados também pelas variações nos desenhos dos estudos, com intenção de escolha versus escolha real, tipo e localização das informações calóricas e dependência de dados alimentares autorrelatados ou obtidos a partir da venda dos alimentos, não podendo ser avaliado o consumo real (ABEL et al., 2014).

É importante ressaltar que para que fosse realizada a rotulagem dos cardápios, os restaurantes precisaram calcular o valor nutricional das preparações, o que evidenciou, em alguns estudos, preparações com alta densidade energética e/ou alto teor de gorduras e sódio (KERINS et al., 2016; MAZOCCO et al., 2018). Nesse sentido, Feldman et al. (2015) realizaram um estudo que avaliou a acurácia da informação nutricional de alimentos servidos numa universidade. Segundo os autores, houve grande variação entre as informações nutricionais publicadas pelos restaurantes e a que foi aferida durante o estudo, assim como com relação ao tamanho da porção. Portanto, não basta informar o valor nutricional, é preciso garantir que as informações estejam corretas, independentemente da forma de apresentação escolhida, ou as decisões baseadas nelas não seriam benéficas ao consumidor.

\section{CONSIDERAÇÕES FINAIS}

Foram analisados diversos estudos que avaliaram a rotulagem de cardápios como ferramenta a ser utilizada para auxiliar o consumidor na escolha de alimentos mais saudáveis. A maioria dos artigos discute os resultados da rotulagem a partir de mudanças percebidas no consumo, ou na intenção de consumo de energia durante as refeições. Entretanto, alguns estimaram também o consumo de açúcares, gorduras, sódio e fibras.

Dentre os estudos que apresentaram mudanças positivas com a rotulagem do cardápio, a maior parte deles comparou mais que um método de exposição das informações nutricionais. A rotulagem exibida com o uso das cores do semáforo e símbolos de indicação de saúde parecem ser mais efetivos que apenas exibir o valor energético das preparações. Essas diferenças talvez possam ser explicadas pela maior facilidade de entendimento das informações quanto apresentadas de forma qualitativa.

Como limitação, os estudos são bastante heterogêneos. Assim, são necessários mais estudos de rotulagem de cardápios em restaurantes institucionais e restaurantes comerciais self-service. 


\section{REFERÊNCIAS}

ABEL, M. L. et al. Consumer Understanding of Calorie Labeling. Health Promotion Practice, v. 16, n. 2, p. 236-243, 31 jul. 2014. Disponível em: http://dx.doi.org/10.1177/1524839914543105. Acesso em: 15 jul. 2020.

BEZERRA, I. N. et al. Alimentação fora de casa e excesso de peso: uma análise dos mecanismos explicativos. Revista Brasileira em Promoção da Saúde, v. 29, n. 3, p. 455-461, 30 set. 2016. Disponível em: http://dx.doi.org/10.5020/18061230.2016. p455. Acesso em: 15 jul. 2020.

BLEICH, S. N. et al. A Systematic Review of Calorie Labeling and Modified Calorie Labeling Interventions: Impact on Consumer and Restaurant Behavior. Obesity, v. 25, n. 12, p. 2018-2044, out. 2017. Disponível em: http://dx.doi.org/10.1002/oby.21940. Acesso em: 15 jul. 2020.

BLEICH, S. N.; WOLFSON, J. A.; JARLENSKI, M. P. . Calorie Changes in Chain Restaurant Menu Items. American Journal Of Preventive Medicine, v. 48, n. 1, p. 70-75, jan. 2015. Disponível em: http://dx.doi.org/10.1016/j.amepre.2014.08.026. Acesso em: 15 jul. 2020.

BRASIL. Ministério da Saúde. Guia alimentar para a população brasileira. 2. ed. Brasília: Ministério da Saúde, 2014. 156 p. Disponível em: https://bit.ly/32Dplbe. Acesso em: 25 jul. 2020.

BRASIL. Ministério da Saúde. Vigitel Brasil 2017: vigilância de fatores de risco e proteção para doenças crônicas por inquérito telefônico. Brasília: Ministério da Saúde, 2018. Disponível em: https://bit.ly/3tHNbgu. Acesso em: 20 maio 2020.

CAVALCANTE, J. B. et al. Ingestão de energia e nutrientes segundo consumo de alimentos fora do lar na Região Nordeste: uma análise do Inquérito Nacional de Alimentação 2008-2009. Revista Brasileira de Epidemiologia, v. 20, n. 1, p. 115-123, mar. 2017. Disponível em: http:/dx.doi.org/10.1590/ 1980-5497201700010010. Acesso em: 17 abr. 2020.

FELDMAN, C. et al. Menu label accuracy at a university's foodservices. An exploratory recipe nutrition analysis. Appetite, v. 92, p. 24-28, set. 2015. Elsevier BV. Disponível em: http://dx.doi.org/ 10.1016/j.appet.2015.05.001. Acesso em: 16 jul. 2020. 
FENG, W.; FOX, A.. Menu labels, for better, and worse? Exploring socio-economic and race-ethnic differences in menu label use in a national sample. Appetite, v. 128, p. 223-232, set. 2018. Disponível em: http://dx.doi.org/10.1016/j.appet.2018.06.015. Acesso em: 15 jul. 2020.

FERNANDES, A. C. et al. Influence of menu labeling on food choices in real-life settings: a systematic review. Nutrition Reviews, v. 74, n. 8, p. 534-548, 29 jun. 2016. Disponível em: http://dx.doi.org/ 10.1093/nutrit/nuw013. Acesso em: 20 jul. 2020.

GORGULHO, B. M.; FISBERG, R. M.; MARCHIONI, D. M. L.. Nutritional quality of major meals consumed away from home in Brazil and its association with the overall diet quality. Preventive Medicine, v. 57, n. 2, p. 98-101, ago. 2013. Disponível em: http://dx.doi.org/10.1016/j.ypmed.2013.04.020. Acesso em: 20 jul. 2020.

INSTITUTO BRASILEIRO DE GEOGRAFIA E ESTATÍSTICA. Pesquisa de orçamentos familiares 2017-2018: primeiros resultados. Rio de Janeiro: IBGE, 2019. 69 p. Disponível em: https://bit.ly/ 3tLoPTc. Acesso em: 20 jul. 2020.

JEONG, J.; HAM, S.. Application of the Health Belief Model to customers' use of menu labels in restaurants. Appetite, v. 123, p. 208-215, abr. 2018. Disponível em: http://dx.doi.org/10.1016/ j.appet.2017.12.012. Acesso em: 20 jul. 2020.

KERINS, C. et al. Effects of an icon-based menu labelling initiative on consumer food choice. Perspectives In Public Health, v. 137, n. 1, p. 45-52, 20 jul. 2016. Disponível em: http://dx.doi.org/ 10.1177/1757913916640826. Acesso em: 15 jul. 2020.

LACHAT, C. et al. Eating out of home and its association with dietary intake: a systematic review of the evidence. Obesity Reviews, v. 13, n. 4, p. 329-346, 23 nov. 2011. Disponível em: http://dx.doi.org/ 10.1111/j.1467-789x.2011.00953.x. Acesso em: 15 jul. 2020.

LEVINGS, J. L.; GUNN, J. P. . From Menu to Mouth: Opportunities for Sodium Reduction in Restaurants. Preventing Chronic Disease, v. 11, 23 jan. 2014. Centers for Disease Control and Prevention (CDC). Disponível em: http://dx.doi.org/10.5888/pcd11.130237. Acesso em: 22 jul. 2020.

MAZOCCO, L. et al. Food Rating Scale in Food Services: From Development to Assessment of a Strategy for Consumer Healthier Choices. Nutrients, v. 10, n. 9, p. 1303-1315, 14 set. 2018. Disponível em: http://dx.doi.org/10.3390/nu10091303. Acesso em: 25 abr de 2020. 
PATIÑO, S. R. G. et al. Effects of Menu Labeling Policies on Transnational Restaurant Chains to Promote a Healthy Diet: a scoping review to inform policy and research. Nutrients, v. 12, n. 6, p. 1544-1571, 26 maio 2020. Disponível em: http://dx.doi.org/10.3390/nu12061544. Acesso em: 15 jul. 2020.

PÉREZ, C. et al. Effect of calorie labeling on menu selection: a preliminary study in Santiago, Chile. Revista Chilena de Nutrición, v. 44, n. 1, p. 6-11, mar. 2017. Disponível em: http://dx.doi.org/10.4067/ s0717-75182017000100001. Acesso em: 15 jul. 2020.

PRATT, N. S. et al. Improvements in recall and food choices using a graphical method to deliver information of select nutrients. Nutrition Research, v. 36, n. 1, p. 44-56, jan. 2016. Disponível em: http://dx.doi.org/10.1016/j.nutres.2015.10.009. Acesso em: 20 jul. 2020.

REALE, S.; FLINT, S. W.. The Impact of Menu Label Design on Visual Attention, Food Choice and Recognition: an eye tracking study. Journal Of Sensory Studies, v. 31, n. 4, p. 328-340, 30 jun. 2016. Disponível em: http://dx.doi.org/10.1111/joss.12216. Acesso em: 15 jul. 2020.

SCOURBOUTAKOS, M. J. et al. Testing a Beverage and Fruit/Vegetable Education Intervention in a University Dining Hall. Journal Of Nutrition Education And Behavior, v. 49, n. 6, p. 457-465, jun. 2017. Disponível em: http://dx.doi.org/10.1016/j.jneb.2017.02.003. Acesso em: 20 jul. 2020.

SEWARD, M. W.; BLOCK, J. P. ; CHATTERJEE, A.. Student experiences with traffic-light labels at college cafeterias: a mixed methods study. Obesity Science \& Practice, v. 4, n. 2, p. 159-177, 14 mar. 2018. Disponível em: http://dx.doi.org/10.1002/osp4.159. Acesso em: 15 jul. 2020.

SEWARD, M. W.; BLOCK, J. P. ; CHATTERJEE, A.. A Traffic-Light Label Intervention and Dietary Choices in College Cafeterias. American Journal Of Public Health, v. 106, n. 10, p. 1808-1814, out. 2016. Disponível em: http://dx.doi.org/10.2105/ajph.2016.303301. Acesso em: 17 jul. 2020.

STRELETSKAYA, N. A. et al. Menu-Labeling Formats and Their Impact on Dietary Quality. Agribusiness, v. 32, n. 2, p. 175-188, 4 dez. 2015. Disponível em: http://dx.doi.org/10.1002/ agr.21444. Acesso em: 15 jul. 2020.

TEMPLE, J. L. et al. Nutrition Labels Decrease Energy Intake in Adults Consuming Lunch in the Laboratory. Journal Of The American Dietetic Association, v. 111, n. 5, p. 52-55, mai. 2011. Disponível em: http://dx.doi.org/10.1016/j.jada.2011.03.010. Acesso em: 23 jul. 2020. 
THORNDIKE, A. N et al.; Calories Purchased by Hospital Employees After Implementation of a Cafeteria Traffic Light-Labeling and Choice Architecture Program. JAMA Network Open, v. 2, n. 7 , p. 196789-196801, 10 jul. 2019. Disponível em: http://dx.doi.org/10.1001/jamanetworkopen.2019.6789. Acesso em: 20 jul. 2020.

TURNWALD, B. P. ; CRUM, A. J.. Smart food policy for healthy food labeling: Leading with taste, not healthiness, to shift consumption and enjoyment of healthy foods. Preventive Medicine, v. 119, p. 7-13, fev. 2019. Disponível em: http://dx.doi.org/10.1016/j.ypmed.2018.11.021. Acesso em: 20 jul. 2020.

USDA. Center for Nutrition Policy \& Promotion. My Plate. Disponível em: https://www.choosemyplate. gov/. Acesso em: 15 ago. 2020.

VIERA, Anthony J. et al. Effects of physical activity calorie expenditure (PACE) labeling: study design and baseline sample characteristics. BMC Public Health, v. 17, n. 1, p. 702-710, 12 set. 2017. Disponível em: http://dx.doi.org/10.1186/s12889-017-4710-0. Acesso em: 20 jul. 2020. 